\title{
Governança e gestão social em redes empresariais: análise de três arranjos produtivos locais (APLs) de confecções no estado do Rio de Janeiro*
}

\author{
Lamounier Erthal Villela** \\ Mario Couto Soares Pinto***
}

Sumário: 1. Introdução; 2. Referencial teórico; 3. Metodologia; 4. Resultados; 5. Conclusões.

Summary: 1. Introduction; 2. Theoretical framework; 3. Methodology; 4. Results; 5. Conclusions.

Palavras-chave: redes empresariais; APLs; governança; gestão coletiva.

KEY WORDs: business networks; local production systems; LPSs; governance; collective management.

Este artigo avalia as dificuldades encontradas em redes empresariais situadas em três cidades do Rio de Janeiro - Cabo Frio, Petrópolis e Nova Friburgo - para a condução de uma governança sustentada na participação e na deliberação dos atores envolvidos nos APLs ali existentes. A teoria de redes empresariais, de APLs e de governança não espelha integralmente a realidade empírica, havendo dificuldades a serem superadas, não previstas nas discussões conceituais. Foram feitas entrevistas com diversos stakeholders de arranjos produtivos do ramo de confecções daqueles

\footnotetext{
* Artigo recebido em abr. e aceito em ago. 2009.

** Pós-doutorando em administração na Escola Brasileira de Administração Pública e de Empresas da Fundação Getulio Vargas (Ebape/FGV), doutor em economia aplicada pela Université Paris III (Sorbonne Nouvelle). Professor titular e coordenador-geral do Programa de Pós-Graduação em Administração e Desenvolvimento Empresarial da Universidade Estácio de Sá (Ppgade), professor adjunto do Mestrado em Economia Empresarial da Universidade Candido Mendes. Diretor da revista científica ADM.MADE. Membro da Câmara de Gestão de APLs do Estado do Rio de Janeiro. Endereço: Av. Presidente Vargas, 642 - CEP 20071-001, Rio de Janeiro, RJ, Brasil. E-mail: lvillela@estacio.br.

*** Doutor em administração de empresas pela Pontifícia Universidade Católica do Rio de Janeiro (PUC-Rio). Mestre em administração de empresas pela PUC-Rio. Professor adjunto da Universidade Estácio de Sá (Made/Unesa). Endereço: Av. Presidente Vargas, 642 — CEP 20071-001, Rio de Janeiro, RJ, Brasil. E-mail: mario.pinto@estacio.br.
} 
territórios, entre eles empresários, representantes dos poderes públicos municipais e estaduais, instituições de apoio empresarial, associações e sindicatos, buscando identificar como se dão os processos de tomada de decisão e de gestão coletiva. Como resultado, foram mapeados problemas relativos à pouca capacidade de gestão dos empresários, extrema heterogeneidade dos stakeholders, em termos tanto de tamanho quanto de interesses, e um grau de confiança ainda incipiente entre os envolvidos, resultando em comportamentos ora predatórios, ora colaborativos, por parte dos empresários.

Governance and social management of business networks: an analysis of three textile industry local production systems in the state of Rio de Janeiro, Brazil This article assesses the difficulties faced by three local production systems (LPSs) in the State of Rio de Janeiro, trying to verify whether or not their reality reflects the theory of governance and business networks. The hypothesis that drives this research is that the reality is not close to the theoretical ideal world, and that there are many issues which were not considered by the conceptual discussions. A field research and a quality analysis were performed. The data was obtained by means of a number of in-depth interviews with stakeholders in textile industry LPSs in the cities of Nova Friburgo, Petropolis and Cabo Frio (such as owners, government representatives and union representatives). According to the analysis, there are many issues that the theory cannot deal with, such as lack of business skills, huge differences among stakeholders, in terms of size and priorities, and an unreliable behavior among these businessmen.

\section{Introdução}

Não é novidade que a ação do Estado deixa lacunas em diversas dimensões relevantes da vida social, seja por falta de recursos, seja por uma capacidade de gestão aquém dos desafios que deve enfrentar. Tal fenômeno não é privilégio do Brasil, mas aqui, por conta da dramaticidade do esgarçamento de sua teia social, toma proporções não triviais, mobilizando diversos setores, formalmente organizados ou não, no equacionamento de tais dificuldades. Como resultado, propostas envolvendo os conceitos de governança, de arranjos produtivos locais (APLs) e, principalmente, de redes empresariais, têm se multiplicado nas discussões acadêmicas e contado com significativo apoio oficial.

Por governança entenda-se o processo de coordenação de atores, de grupos sociais, de instituições ou de redes empresariais para alcançar objetivos discutidos e definidos coletivamente. Esse conceito se engendra em um contexto de descentralização, como induzido pelo ideário neoliberal, e é uma tentativa de se exercitar a corresponsabilidade na gestão de um grupo social, 
estabelecida em um território e capaz de representar interesses coletivos (Le Galès, 2006).

Rede pode ser uma concentração em um território de pequenas e médias empresas, objetivando ganhos de escala (Brener, 2004, citado por Oliveira e Bruni, 2009). Por sua vez, Schmitz (2005:322) entende que este aprimoramento produtivo acaba por "incrementar a posição de competitividade de uma empresa ou de um aglomerado de empresas", ressaltando que há pesquisas apontando que "as empresas que aumentaram a cooperação obtiveram maiores ganhos de desempenho" (Schmitz, 2005:326). Para Mytelka e Farinelli (2005), os aglomerados informais costumam envolver pequenas e microempresas com baixa capacidade de gestão e com nível tecnológico abaixo da média do seu mercado. Tais aglomerações (clusters) se configuram em redes de fraca coordenação e com potencial de desenvolvimento restrito. Oliveira e Bruni (2009) entendem que clusters e APLs são conceitos usados com pouca clareza, muitas vezes intercambiáveis. Conforme apontam os autores, há características em comum entre eles, tais como "a interação entre firmas, a proximidade geográfica e/ou setorial entre empresas e um maior ou menor grau de concentração entre pequenas e médias empresas" (Oliveira e Bruni, 2009:4). Tais processos colaborativos recebem nomes e tipologias distintas, conforme asseveram Maehler e Cassanego Jr. (2009). Esses autores entendem que tais cooperações são estudadas sob várias denominações e listam os trabalhos "sobre 'joint ventures', como os de Kogut (1988, 1991); 'redes', em Cassiolato Filho e Pires (2001); 'alianças', em Lorange e Roos (1996), Yasuda e Iijima (2005), Ireland e colaboradores (2002), 'clusters' em Porter (1998), entre outros", como exemplos (Maehler e Cassanego Jr., 2009:2).

Desta discussão, apreende-se que os APLs são redes empresariais que se configuram em aglomerações espaciais, com capacitações produtivas específicas, e que mantêm entre si vínculos tangíveis e/ou intangíveis, fracos ou intensos (Lastres e Cassiollato, 2006). As localidades em que estão concentradas tais redes empresariais frequentemente possuem, entre seus habitantes, pessoas dotadas de conhecimento e capacitações fundamentais para uma produção específica, fato que facilita significativamente o desenvolvimento econômico da coletividade. Tais arranjos devem, teoricamente, elaborar uma governança capaz de conciliar interesses, nem sempre convergentes, dos diferentes atores; planejar conjuntamente e executar ações cooperadas que promovam o desenvolvimento de suas atividades empresariais e consequentemente do local em que se radicou. $\mathrm{O}$ processo de discussão e diálogo entre cepas tão diversas quanto o setor público, o mercado e a sociedade civil, vem sendo apontado como uma resposta plausível às fragilidades da ação do Estado na transforma- 
ção de uma realidade social eivada de necessidades prementes. Tal expectativa está lastreada na suposição de que as redes empresariais, ao envolver diferentes players na construção, ou na tentativa de se construir objetivos comuns, podem viabilizar ações e práticas comunitárias transformadoras e dialógicas, valorizando os recursos locais e superando os obstáculos impostos pelos mercados globalizados.

Em uma análise histórica sobre a formação dos atuais APLs existentes no estado do Rio de Janeiro, pode-se observar que tais capacitações perduraram a diferentes estruturas empresariais. Logo, as empresas locais tanto demandam quanto capacitam continuamente os habitantes de determinada comunidade, alimentando e sendo alimentada por conhecimentos coletivamente construídos. Deve-se observar, contudo, que se trata de uma ação não linear, capaz de englobar a criação e a destruição de organizações e de conhecimentos, típica de um processo de aprendizagem. As empresas novatas e as sobreviventes, em diferentes ciclos, apresentam estruturas organizacionais distintas, cuja evolução tende continuamente a fortalecer as ligações entre as empresas e a reestruturar laços relacionais. No entanto, o desenvolvimento dessas redes empresariais não está apenas salvaguardado por capacitações técnicas, mas pela capacidade conjunta das empresas se manterem competitivas. Assim, a cooperação, as ações conjuntas e a formulação proativa de estratégias da rede se tornam fundamentais para a sustentabilidade do APL.

As redes empresariais, a priori, são movidas por lógicas funcionais, ou seja, os processos são negociais e representam um direito de se organizarem e de formarem associações profissionais (Heinelt e Kübler, 2005). A prática mostra que o impacto socioeconômico nos municípios onde estão localizadas necessariamente atrai outros participantes para a governança do APL. Poderes públicos municipais e estaduais, instituições de apoio empresarial, tais como o Sebrae e o Senac, associações, sindicatos, instituições de ensino, instituições bancárias, entre outras, são atores coadjuvantes, mas efetivamente participantes das redes empresariais em tela. Dada a dificuldade de alinhamento dos interesses de tantos envolvidos, a complexidade de suas culturas e de seus valores e, principalmente, as suas relações de interdependência, que estão diluídas em uma miríade de pequenas e micro empresas (PMEs), a capacidade de se construir uma gestão social, verdadeiramente participativa e deliberativa, condutora de uma governança em APLs transformadores, na prática vem se mostrando bastante complexa, quiçá longínqua, e distante do encaminhamento, ora burocrático, ora romântico, que lhe é emprestado por órgãos governamentais e por alguns de seus divulgadores. 
Tal quadro torna-se ainda mais ininteligível na medida em que a ele é possível: anexar novas tecnologias de informação e de comunicação (TIC), que alteram substancialmente as relações empresariais; a existência de elevada flexibilidade produtiva, baseada em redes de subcontratações e especializações em cadeias produtivas, o que afeta o sentido de coletivo percebido; implantar políticas públicas voltadas ao desenvolvimento de aglomerações produtivas, o que empresta um colorido burocratizante e tecnocrata às iniciativas. Todavia, dialeticamente, observa-se que a não participação nas redes pode significar exclusão, ainda que a interdependência gere fragilidade e subordinação das pequenas empresas em relação às grandes. Além disso, a superespecialização das cadeias produtivas demanda investimentos contínuos em tecnologias e capacitação de pessoal, na maioria das vezes inacessível às pequenas empresas e às comunidades locais.

Em síntese, existem importantes dificuldades de adequação da realidade local, entendida como APLs e/ou rede de PMEs, às demandas de mercado, frustrando expectativas e negando algumas previsões mais otimistas em relação ao seu potencial inovador. Para dar conta de tal discrepância, este artigo procura responder à seguinte questão: quais as dificuldades encontradas, nas redes empresariais estudadas, para condução de uma governança sustentada na participação e na deliberação dos atores envolvidos nos APLs ali existentes?

Para responder à questão, a investigação focou nas práticas de gestão coletiva de três arranjos produtivos locais de confecções, a partir de amostras de redes de empresas situadas em Petrópolis, Nova Friburgo e Cabo Frio. O estudo se delimita ao foco da gestão participativa existente na governança dos APLs acima citados, ou seja, na forma como tais redes organizam seus processos decisórios deliberativos, e como se dá a participação dos atores na construção de suas inter-relações.

Como se pretende uma análise crítica, elaborada a partir da confrontação entre a teoria e a prática, na segunda seção deste artigo, serão elencados aspectos teóricos que fundamentam o estudo e permitem elucidar como poderiam ser as práticas de governanças dos APLs para, mais adiante, serem contrapostos à realidade encontrada no campo. Em seguida, serão descritos os aspectos metodológicos, baseados em análise qualitativa, com dados obtidos em pesquisa exploratória e de campo, onde foram aplicados questionários e elaboradas entrevistas. Os sujeitos das pesquisas foram os empresários, os representantes de poderes públicos, dirigentes de associações e de instituições locais. Na quarta seção são apresentados os resultados e, por último, são tecidas as conclusões que respondem à pergunta proposta. 


\section{Referencial teórico}

Os aspectos teóricos que embasam este artigo estão encadeados na seguinte lógica: redes empresariais $\rightarrow$ APLs $\rightarrow$ governança $\rightarrow$ gestão social participativa $\rightarrow$ desenvolvimento local. A sequência sugere a interdependência de tais dimensões, de acordo com o foco da investigação. Assim, entende-se que, das redes especializadas, surgem os APLs, que necessitam de um governo participativo e não mais hierárquico, caracterizando uma governança. Como consequência, visando beneficiar os interesses dos diversos atores envolvidos, cria-se uma sustentabilidade nos processos, que acaba por viabilizar o desenvolvimento local em suas diferentes óticas.

Uma rede é constituída de um conjunto de unidades sociais que mantêm relações entre si, direta ou indiretamente, por meio de cadeias de tamanhos e estruturas variáveis (Mercklé, 2004). Normalmente, elas constituem um conjunto aglomerado espacialmente e apresentam, além das similaridades, ligações tangíveis e intangíveis em sua produção. A recente literatura sobre redes empresariais as classifica como uma nova estrutura organizacional, ou seja, um fenômeno que alterou as formas de produção do mundo contemporâneo (Castells, 2007; Granovetter, 2000). É possível afirmar que as estruturas organizacionais em rede estão presentes em diversas atividades econômicas contemporâneas, sob múltiplas arquiteturas e variações. Como exemplo, é possível citar os grandes conglomerados transnacionais, as redes bancárias, os sistemas de infraestrutura, em especial o elétrico, as malhas viárias etc., ancorados, sobretudo, nos avanços das tecnologias de informação e de comunicação (TICs). Não por acaso, Castells (2007) delineia uma sociedade contemporânea centrada no uso e aplicação de informação e conhecimento, cuja base é alterada pela revolução tecnológica, que é baseada na tecnologia da informação e provoca alterações profundas nas relações sociais, nos sistemas políticos e nos sistemas de valores globais. Tais avanços permitem às empresas operar em todo o mundo e, em tempo real, elaborar manobras a distância capazes de alterar instantaneamente sua cadeia produtiva (Gonçalves, 2002). Tais organizações alicerçam sua produção em territórios nacionais e imediatamente constroem redes de fornecedores e de revendedores de alcance planetário, que trabalham segundo suas demandas. Gereffi (1998) propõe a existência de dois tipos de cadeias produtivas: as producer driven commodity chains - comandadas por produtores - e as buyer-driven commodity chains - lideradas pelos compradores. Essas cadeias criam facilidades e aumentam a flexibilidade produtiva, pois a estrutura em rede lhes permite uma ampliação de empresas especialistas, de diferentes portes, auxiliando-as na composição e na complementaridade do cenário produtivo. 
Por sua vez, Hitt e colaboradores (2005), com uma visão de estratégias empresariais, denominam redes de alianças o conjunto de parcerias múltiplas estabelecidas por empresas com a finalidade de atingir objetivos compartilhados. Segundo os autores, isso ocorre porque, em geral, a maioria das empresas não possui todos os recursos e capacidades necessários para atingir seus objetivos, o que faz com que em algumas situações a cooperação entre empresas crie mais valor do que a competição entre elas. Teoricamente, as redes são mais efetivas quando: reúnem empresas localizadas em uma mesma região; envolvem também relacionamentos e interações sociais entre os parceiros; e quando existe uma organização que funciona como centro estratégico.

Segundo Détrie (1999), a estrutura em rede é uma forma de organização que permite às empresas responderem de modo eficaz a situações complexas e de grande incerteza. As redes geram flexibilidade, pois os nós com suas devidas especializações permitem rápidas mudanças e inovações nos processos. No entanto, as condições de sucesso e de desenvolvimento das redes estão relacionadas a aspectos subjetivos como a motivação e o comprometimento dos atores envolvidos. Logo, um fator determinante do sucesso é o engajamento voluntário dos atores nas atividades que lhes são designadas, assim como sua forma de integração no grupo. Sem o devido engajamento e participação, inexiste uma adaptação aos novos modos de produção, necessária ao trabalho sinérgico. Os sistemas de informação e de controle, mais do que em outro tipo de estrutura, devem ser transparentes e fluidos. A qualidade do processo deve ser analisada pelos resultados (output) obtidos a posteriori. Para essa realidade, a prática de um método de controle tradicional, de viés taylorista, mostrase ineficaz, dado que, nessa rede complexa e interdependente é difícil detalhar e individualizar os meios para se alcançar os resultados. Assim, destaca-se a necessidade de se consolidar elos de confiança entre os atores envolvidos. Se os meios não podem ser individualmente controlados, supõe-se, a priori, que as relações de confiança entre os atores inibam as situações oportunistas dos participantes de um grupo. Assim, uma vez quebrada a desconfiança entre os participantes, amplia-se a possibilidade de sucesso da estrutura e de institucionalização da rede. Não por acaso, assevera Junqueira (2002:6-7) que

a criatividade e a compreensão são mais importantes que a certeza e a predição. As redes, no universo de mudanças, surgem como uma linguagem de vínculos, das relações sociais entre organizações que interagem mediadas por atores sociais que buscam entender de maneira compartilhada a realidade social. São formas de agir que privilegiam os sujeitos. 
Segundo Britto (2002), os elementos estruturantes de uma rede são os nós (organizações ou atividades), as ligações (relacionamento entre organizações), os fluxos (de bens e informações) e as posições (estrutura de divisão do trabalho). A forma, então, com que se estrutura uma rede depende das conexões entre os nós, o que permite uma flexibilidade na ação conjunta da estrutura desejada. Logo, o potencial de combinações entre os nós depende da coesão e das necessidades de compartilhamentos. Balestrin e Vargas (2003) definem quatro tipos de redes de empresas:

v as verticais, com dimensão hierárquica, a exemplo das empresas automotivas com uma vasta rede de subcontratações;

v as horizontais, configurando-se na dimensão da cooperação, tal como sugerido na governança dos APLs;

- as redes formais, criadas por contratos entre empresas e/ou instituições como, por exemplo, as alianças estratégicas;

v as informais, comuns às aglomerações comerciais, em que as empresas se beneficiam do conhecimento comum ao aglomerado.

Considerando que as redes horizontais são constituídas por empresas que se mantêm independentes entre si na condução de suas estratégias mercadológicas, na gestão de informação e de tecnologias e em seus objetivos organizacionais, há um processo cooperativo que caminha em paralelo à competição entre seus membros, o que facilita a liberdade de ação individual simultaneamente com as ações coletivas. Da mesma forma, as redes informais trazem uma dimensão de conivência entre atores que têm preocupações semelhantes, sem que seja necessário qualquer tipo de contrato formal que estabeleça regras ou procedimentos. É a confiança entre os atores e a conformidade dos interesses comuns que viabilizam a cooperação e a estruturação de relações interempresariais. Justamente por conta dessas características é que a realidade dos APLs mais se aproxima de redes com os perfis horizontais e informais descritos.

A literatura especializada em rede pode ser ainda mais específica quando se trata, por exemplo, da economia das redes (Currien, 2005), ou da sociologia das redes sociais (Mercklé, 2004), ou ainda da gestão de redes (Fleury e Ouverney, 2007). Neste artigo, os aspectos enfocados tendem à transdisciplinaridade, pois o objetivo é compreender as relações que fundamentam a complexidade dos interesses dos atores. Nesse sentido, convém explicitar o conceito de APL. 
Relembrando a definição de Cassiolato e Lastres (2003), APLs são aglomerações territoriais de agentes econômicos, políticos e sociais, com foco em um conjunto específico de atividade econômica, que apresentam vínculos, mesmo que incipientes. A liderança é exercida com a participação e a interação de empresas, que podem ser desde produtoras de bens e serviços finais até fornecedoras de insumos e equipamentos, prestadoras de consultoria e serviços, comercializadoras, clientes, entre outros, e suas variadas formas de representação e associação. Incluem, também, diversas outras instituições públicas e privadas voltadas para a formação e a capacitação de recursos humanos (tal como escolas técnicas e universidades), pesquisa, desenvolvimento e engenharia, política, promoção e financiamento que irão se articular para constituir a governança do local. Os estudos do Sebrae (2004) identificam os APLs pelas concentrações de atividades econômicas similares ou aglomerações produtivas em uma mesma localidade, caracterizadas pelo padrão de especialização. É utilizado na identificação das concentrações o Cadastro Nacional de Atividades Econômicas (Cnae), que usa duas fontes de informações: a relação anual de informações sociais (Rais) e o cadastro do IBGE (Sebrae, 2004:13). Resumindo, é possível afirmar que um APL é uma rede de empresas aglomeradas em um território e com uma produção específica, contando com o apoio de instituições de diversos matizes.

As atuais redes organizacionais, segundo Villela (2005), representam o fim do isolacionismo das organizações, como no período fordista, e a quebra de paradigma da administração clássica sobre as hierarquias organizacionais. Tal conceito suscita mudanças, seja na estrutura organizacional, seja no estilo de gestão e na forma de organização das relações entre as empresas que se tornam interdependentes. Logo, uma gestão hierárquica clássica não tem espaço em um APL, pois são diversos atores que buscam representar, ainda que teoricamente, os seus interesses. Nesse sentido, a liderança é dada por uma governança e não mais por um governo. Governança passa a ser então a prática de uma gestão compartilhada de processos decisórios que conduz, a partir do consenso, as deliberações de uma dada rede, objetivando articular e facilitar ações do projeto de desenvolvimento traçado pelos próprios participantes. Assim, as decisões devem ser tomadas em conjunto, devido ao engajamento participativo de todos os envolvidos, sejam eles representantes do Estado, da sociedade civil e/ou das empresas.

Tenório (2007:19) assevera que "a terminologia contemporânea começa a conotar conceitos como governança, que enfatiza o papel dos cidadãos - individuais ou organizados em formas associativas - no processo político, partindo da identificação dos problemas, à formulação, instituição e avaliação 
dos resultados". O objetivo dessa liderança é obter uma participação efetiva dos diferentes grupos de interesse e de comunidades nas decisões. Isso requer uma contextualização cultural do processo decisório, de maneira que, além da abertura que permite a participação democrática dos diversos atores, esse processo possibilite um fluxo de informações em todos os sentidos, permitindo que os diversos setores recebam informações e participem da elaboração dos planos que serão implementados. A realidade administrativa não pode considerar os atores envolvidos em uma política pública apenas individualmente, mas como um conjunto conectado e interdependente, com a interação de diferentes agentes.

Essa proposta se afasta da estrutura tradicional, em que uma grande empresa exerce a liderança, na medida em que funciona como ponto central ou eixo $(h u b)$. Nesse caso, a governança se dá por meio de formas "hierárquicas", com a empresa líder governando as demais existentes na estrutura (Britto, 2002). Tal modalidade é muito comum no caso das empresas do setor automotivo, em que as montadoras são demandantes de uma imensa rede - buyer-driven commodity chains - lideradas pelos compradores.

Por seu turno, os APLs apresentam a modalidade de governança "heteroárquica" (Heinelt e Kübler, 2005), que se caracteriza por um importante número de atores que negociam continuamente os compromissos assumidos pelos grupos. Nesse caso, as decisões pela unanimidade são improváveis, o que significa dizer que as redes "heteroárquicas" representam um vetor importante para as políticas deliberativas, nas quais as decisões são fundamentadas pela compreensão de intersubjetividades. Segundo Fischer (1996:19), "governance é um conceito plural, que compreende não apenas a substância da gestão, mas a relação entre os agentes envolvidos, a construção de espaços de negociação e os vários papéis desempenhados pelos agentes do processo".

Tenório e colaboradores (2008) ressaltam que os processos decisórios participativos, conforme ocorrem em uma governança, no âmbito das esferas públicas, devem refletir os conceitos de cidadania deliberativa, segundo os termos de Habermas (1987). De acordo com os autores, a expressão "legitimidade das decisões políticas deve ter origem em processos de discussão, orientados pelos princípios da inclusão, do pluralismo, da igualdade participativa, da autonomia e do bem comum" (Tenório et al., 2008:9), o que exige um amadurecimento daqueles encarregados em conduzir processos participativos que intentem deliberação.

Dadas as questões teóricas acima apontadas, é notório existir uma forte relação entre o conceito de governança e o de racionalidade comunicativa, pensado por Habermas (1987), visto que a sua conjunção é capaz de estabele- 
cer vínculos democratizadores nas relações sociais. Nesse sentido, as relações devem ser dialógicas e não mais monológicas. É por intermédio do diálogo que se elabora o consenso entre os indivíduos; tal consenso busca o bem comum e a participação dos atores envolvidos em uma determinada ação. O monólogo, ao contrário, se expressa pelas relações de autoridade e de definição de níveis hierárquicos, com rigidez de papéis, agredindo o conceito de governança. Assim, os atores envolvidos em uma dada governança discutem seus projetos e definem seus objetivos comuns, na solução de problemas que conduzam às convicções dos atores envolvidos. Uma vez que os envolvidos são corresponsáveis pelas ações, eles devem ser conscientes das necessidades da coletividade e do bem comum, ou seja, devem ser guiados pela racionalidade substantiva, ou seja, a base da vida humana ética e responsável. Segundo Guerreiro Ramos (1989:22),

a teoria corrente da organização dá um cunho normativo geral ao desenho implícito na racionalidade funcional. Admitindo como legítima a ilimitada intrusão do sistema de mercado na vida humana, a teoria da organização atual é, portanto, teoricamente incapaz de oferecer diretrizes para a criação de espaços sociais em que os indivíduos possam participar de relações interpessoais verdadeiramente autogratificantes.

Dessa forma, a experiência atual demonstra que a gestão em redes deve ser participativa e dialógica, e não mais tecnoburocrática e hierarquizada, como eram as formas de intervenção do Estado no século passado. Portanto, quando se objetiva alcançar o desenvolvimento local, os problemas socioeconômicos não podem mais ser resolvidos pela ação independente do Estado, o que traz à baila uma rediscussão sobre o papel da gestão pública. A aproximação da governança com a democracia enfatiza a necessidade de gerenciar o setor público de modo transparente (accountability), participativo, criativo e responsável, combinando a ação interorganizacional com um grande conjunto de relações, que podem ser estabelecidas entre governos, empresas, ONGs, associações comunitárias etc.

Dada a complexidade que caracteriza os atuais processos de desenvolvimento, a discussão de redes e de governança é fundamental para se entender o conceito de desenvolvimento local, que pressupõe melhorias da qualidade de vida substantiva e instrumental de determinada localidade.

O processo de desenvolvimento local requer o envolvimento "multidimensional" dos aspectos econômicos, sociais, culturais, ambientais, físico-territoriais, político-institucionais e científico-tecnológicos. No processo, essas 
dimensões são interdependentes e trarão como consequência a crescente participação dos diversos atores locais.

O desenvolvimento local tanto requer mudanças como transforma a estrutura socioeconômica local. Tais transformações necessitam das ações orquestradas do Estado, do mercado e da sociedade civil. Teoricamente, os representantes das diferentes esferas devem compreender conjuntamente suas possibilidades e seus limites de ação, buscando negociar os conflitos de interesses existentes. A identificação desses limites e conflitos é também um meio de entender as "múltiplas dimensões" dos recursos e vocações locais que são fundamentais para a sustentabilidade socioambiental do local em questão. Esse percurso da sustentabilidade requer a prática dialógica, que embasa a negociação continua entre os atores.

Segundo Tenório (2007), quando se aborda o tema desenvolvimento local, deve-se considerar todos os aspectos de inter-relacionamento dos diversos atores da sociedade. Logo, torna-se necessária uma profunda transformação das relações sociais, ou seja, a ampliação da racionalidade substantiva referente às práticas locais. Tal esforço demanda um alargamento do tradicional foco em processos sociais e técnicos de produção, incluindo a preservação ambiental, já que a sustentabilidade do território é mister para a sobrevivência da rede ali estabelecida, pois é nele que são exercidas suas vocações, possibilidades e condições.

Nesse contexto, existe uma mudança nas relações políticas locais, pois os processos de desenvolvimento local interdependem dos esforços exercidos tanto pelas entidades estatais quanto pela sociedade (Gilly e Pecquer, 1995), visto que ambos deverão levar adiante projetos surgidos a partir de interesses coletivos oriundos das discussões. O desenvolvimento local necessita de ações de cidadania, do reconhecimento por parte dos agentes de como suas ações influenciarão na valorização dos recursos e potencialidades do território em questão, e como essas ações irão promover a qualidade de vida da população.

Em resumo, as ações do desenvolvimento local são interdependentes das forças locais, e estas representam o desejo e a capacidade dos interessados em formular e implementar ações que elaborem mudanças no status quo. Nesse contexto, as inter-relações ativas dos atores envolvidos devem assegurar a sustentabilidade do território, segundo as suas condições naturais e/ou vocações.

\section{Metodologia}

Trata-se de investigação de cunho qualitativo, com finalidade aplicada e de análise crítica, de avaliação da teoria na prática. Para tanto, contou-se com 
uma pesquisa bibliográfica, que compôs o referencial teórico; com pesquisa telematizada, pois em sites da internet também foram obtidos dados sobre os APLs de Cabo Frio, Nova Friburgo e Petrópolis. Além disso, a pesquisa pode ser caracterizada como documental e de campo.

No que tange à coleta de dados, foram aplicados questionários e realizadas entrevistas semiestruturadas e abertas para aferir a situação dos itens em estudo junto a empresários e também a integrantes da governança dos APLs (representantes de conselhos, de instituições públicas e da sociedade civil), que se dispuseram a participar da pesquisa.

Os roteiros das entrevistas e questionários foram elaborados a partir dos critérios participativos definidos pelo Pegs/Ebape (Tenório et al., 2008), definidos pelas seis categorias analíticas: processo de discussão; inclusão; pluralismo; igualdade participativa; autonomia; bem comum. Os questionários foram formulados com 46 perguntas, e depois desdobrados em questionários focados para empresários, para conselheiros participantes da governança e para a sociedade civil.

Os arranjos produtivos locais são constituídos: em Cabo Frio, por cerca de 200 empresas atuantes na produção de moda praia; em Nova Friburgo, por cerca de 800 empresas de produção de moda íntima; e, em Petrópolis, por cerca de mil empresas, sendo 190 filiadas à associação de empresários e 60 aos sindicatos das indústrias.

Foram entrevistados 60 empresários dos 120 contatados, destacando-se a característica de micro e pequenas empresas dessa amostra. Além dos empresários, foram entrevistados 17 representantes das governanças dos APLs como poderes públicos locais, Senai, Sebrae e Senac.

As dificuldades enfrentadas para a coleta de dados junto aos sujeitos pesquisados não se resumiram ao fato de terem sido procuradas 120 empresas e apenas 60 terem respondido aos questionários, conforme já exposto, mas também se manifestaram no difícil entendimento por parte dos empreendedores entrevistados a respeito da importância do tema.

\section{Resultados}

\section{Características dos APLs estudados}

O início das atividades econômicas ligadas à moda praia em Cabo Frio pode ser identificado a partir de iniciativas individuais na década de 1950, que se materializaram em empresas familiares, que difundiram seu modo de produ- 
ção e tecnologia por meio da dispersão do saber entre os empregados que, aptos e capitalizados, montaram seus próprios negócios, conforme informado no sítio do Sindivest (www.sindivest.org.br). Já em meados da década de 1980 um grande número de empresas havia se instalado em um mesmo local, a rua José Rodrigues Povoa ou rua da Gamboa, hoje conhecida como a "rua dos biquínis". A partir da segunda metade da década de 1990, a "rua dos biquínis" começou a receber melhorias na sua infraestrutura e hoje constitui o Gamboa Shopping, concentrando dezenas de lojas e fábricas de roupas de praia as mais variadas, contando atualmente com mais de 150 estabelecimentos, embora alguns empresários detenham grupos de até oito lojas. A Associação Comercial e Industrial da rua dos biquinis (Acirb) congrega a maioria dessas empresas e se volta para ações ligadas à infraestrutura e logística da rua dos biquínis. Segundo Valle (2007), participavam em 2007 da governança do APL o Sebrae, a Federação das Indústrias do Estado do Rio de Janeiro (Firjan), a Prefeitura Municipal de Cabo Frio, a Faculdade da Região dos Lagos (Ferlagos), o BB, a Associação Comercial, Industrial e Turística de Cabo Frio (Acia), entre outros.

A constituição do APL de Nova Friburgo remonta à instalação na região de uma empresa de capital estrangeiro, nos idos dos anos 1960. Nos anos 1980, a década perdida na economia nacional, uma série de demissões ocorreu na empresa e funcionárias, na sua maioria com pouco capital e certo conhecimento do ofício, iniciaram pequenos negócios próprios no âmbito de suas residências, o que acabou resultando na instalação de pequenas empresas dedicadas à confecção, com produção destinada ao mercado de moda íntima (Veiga, 2006). Em 1997, a Firjan e o Sebrae encomendaram à Fundação Getulio Vargas (FGV) um estudo sobre as potencialidades econômicas do estado do Rio de Janeiro e a vocação da cidade de Nova Friburgo foi confirmada. A cidade passou a ser um polo, congregando municípios como Bom Jardim, Cantagalo, Cordeiro, Duas Barras e Macuco. Em 2001, o APL foi contemplado com recursos do Banco Interamericano de Desenvolvimento (BID) e consolidou sua vocação para a moda íntima, conforme o sítio do APL de Nova Friburgo (www.intimafriburgo.com.br). O Conselho da Moda de Nova Friburgo, estrutura de governança do polo criada em 2002 e redesenhada em 2003 com a entrada de novos integrantes, hoje é formado por representantes das prefeituras dos municípios envolvidos, do Sebrae/RJ, da Firjan, do Sindicato da Indústria do Vestuário de Nova Friburgo (Sindvest), do BB, do Ministério do Desenvolvimento, Indústria e Comércio (MDIC) e do Serviço Nacional de Aprendizagem Industrial (Senai), conforme está no site do APL. Nesse APL, o número de microempresas no início dos anos 1990 foi de aproximadamente 
3 mil, patamar que foi gradativamente cedendo até chegar ao nível atual, de cerca de 800 empresas, já considerando as formais e as informais. Destas, 70 estão hoje organizadas em consórcios de cooperados que visam às exportações. Observa-se então, desde o boom de confecções nos anos 1990, uma redução contínua do número de empresas, assim como uma concentração na produção em algumas que, pelas características locais, podem ser classificadas como de porte médio.

O polo de confecções de Petrópolis é originário das antigas indústrias têxteis que se instalaram na região desde o final do século XIX e que dominaram o cenário empresarial de Petrópolis até aproximadamente 1960. Com o fechamento destas grandes empresas têxteis, a vila operária da fábrica Dona Isabel, localizada na rua Teresa, transformou-se na rua das malharias. Os ex-operários montaram em suas casas pequenas malharias que transformaram em pontos de venda. Petrópolis se especializou em malharias, e algumas dessas fabriquetas se transformaram em empresas de grande e médio portes. Porém, no início dos anos 1990, com o processo de abertura da economia, as malharias tornaram-se pouco competitivas. Quase todas foram fechadas e, dos egressos destas, iniciou-se uma nova fase - a de confecções de pequeno porte, com produção baseada em serviços terceirizados, denominadas facções. Atualmente, o polo de confecções da rua Teresa conta com aproximadamente mil empresas, cerca de 600 formais, que geram 30 mil empregos diretos e indiretos. A governança local é formada pelos representantes da Associação dos Empresários da Rua Teresa (Arte), da Associação dos Empresários do Bingen, da Central Eletrônica de Negócios, da Firjan/Senai Moda, da prefeitura de Petrópolis, do Sindicon e do Sebrae/RJ.

Como aspectos em comum, os APLs estudados têm o mesmo ramo de atuação, confecções, e surgiram de modo espontâneo, ou seja, sem a intervenção pública. Tais polos produtivos são decorrência de um conhecimento especializado da população local em determinada linha de produção, que é resultado de um domínio técnico acumulado não desprezível, englobando vocações e habilidades específicas. O mais antigo é o das malharias de Petrópolis, porém, devido às grandes mudanças nas estruturas produtivas, até recentemente não contava com uma governança organizada.

As estruturas de governança são recentes nas três localidades, e todas surgem com apoio de instituições públicas, como as prefeituras, o Sebrae e a Firjan (Villela et al., 2004). Ainda que recentes, as governanças possuem diferentes graus de maturidade, com destaque para Nova Friburgo, que, segundo as pesquisas, possui maior quantidade de ações conjuntas e cooperadas. Por sua vez, a experiência de Petrópolis ainda está em estágio inicial, e a 
de Cabo Frio, incipiente. O cenário empresarial é dominado por pequenas e microempresas (PMEs), porém, no caso de Nova Friburgo, há uma tendência à concentração da produção em empresas de pequeno e médio portes. A estrutura intraorganizacional, contudo, é bastante diferente, pois em Petrópolis a produção é baseada em redes de facções, ou seja, terceirizada.

\section{A governança em três exemplos}

É possível identificar um eixo comum de depoimentos nos três APLs estudados, com pequenas variações provenientes das peculiaridades históricas de cada um. No caso de Petrópolis, a participação nas reuniões, decisões e sugestões nos APLs foi apontada pelos empreendedores como muito pequena. Como justificativa, foram várias as alegações, desde "centralismo de decisões nos órgãos participantes das governanças", que levariam "soluções prontas e formatadas", segundo um entrevistado, até questões como falta de "espírito de conjunto", "situações concorrenciais acirradas", inclusive com acusações de "pirataria" interna quanto aos produtos ali fabricados. Também no aspecto mercadológico, foram frequentes as acusações de guerra de preços, muitas vezes calcada em queda de qualidade e em informalidade, disputas por espaços dentro e fora do APL, o que foi atribuído, na opinião dos entrevistados, "à falta de visão e formação do empresariado local". Outros itens, tais como a "desarticulação da governança" e "interesses particulares e de órgãos públicos", sem o devido surgimento "endógeno" das ideias e inovações, também foram apontados como causas da baixa participação e interação entre os empresários dos arranjos produtivos locais pesquisados.

Tais afirmações estão associadas à percepção de que, por vezes, são convocados apenas para "referendar" ou "legitimar" ações e estratégias já definidas por um pequeno grupo. Esse sentimento de desconfiança está exemplificado no fato de que nenhum dos entrevistados reconhece uma participação intensa da sociedade civil nas decisões, o que reduz a transparência do processo decisório. Ratifica esse viés a ausência de consenso entre os entrevistados acerca do estabelecimento das prioridades e no acompanhamento das decisões tomadas, ficando as respostas dispersas de forma fragmentada pelas diversas opções apresentadas nas perguntas. Interessante notar que, do ponto de vista dos empresários, a maioria afirma que "todos participam", mas do ponto de vista de quem faz parte do conselho gestor, esse grupo é o verdadeiro elemento decisor. Aparentemente, cada um entende e vivencia o processo de forma distinta, talvez pelos pontos de vista e interesses diferenciados. Curio- 
samente, a larga maioria dos entrevistados afirmou que as decisões conjuntas são viáveis, rentáveis e possíveis.

No que se refere à defesa de seus interesses, o grupo de Petrópolis também não se mostrou coeso. Enquanto os integrantes do conselho gestor mostraram-se divididos, metade entendendo que os empresários o fazem, e metade discordando, os empresários entrevistados concordaram em larga maioria, superior a $90 \%$. Praticamente um consenso existe no que se refere à percepção da ação da comunidade na defesa de seus interesses, com mais de $2 / 3$ dos entrevistados, de qualquer origem, afirmando que tal defesa existe na prática. Talvez uma noção de "comunidade externa coesa e atuante" faça parte de um imaginário coletivo, mas o cotidiano de convivência entre players distintos imponha um dado de realidade menos monolítico e mais conflitante.

Percepções semelhantes foram encontradas no APL de Cabo Frio. Para apenas $13 \%$ dos empresários entrevistados, o comparecimento nas reuniões dos APLs é significativo, com a maioria das repostas (53\%) apontando para uma ausência recorrente das empresas nas reuniões. Eles mesmos afirmam não frequentar as reuniões por diversas razões. Todavia, daqueles que afirmaram participar mais intensamente, $60 \%$ julgam que suas opiniões são ouvidas, e um entrevistado assinalou que, apesar de ouvidas, suas sugestões não são "praticadas", pois as decisões dependem do interesse da maioria. Uma vez mais um conflito de interesses, velado ou explícito, entre os múltiplos atores apresenta-se, enfraquecendo a noção de unidade presente no conceito de arranjo.

Outro empresário asseverou que uma sugestão sua foi ouvida e foi formada uma comissão para implementá-la. Mas ele "não sabe o resultado ainda", pois não acompanhou mais o processo. Nessa mesma linha de participação transformadora, um entrevistado afirmou que a instalação de um caixa eletrônico do BB na "rua da Gamboa" foi ideia surgida em reuniões do APL. Do ponto de vista de atuação na dimensão financeira, foi possível identificar nesse APL uma postura pouco ativa ante os bancos, já que foi reconhecida por apenas $14 \%$ dos entrevistados e $20 \%$ afirmaram que sequer existem tais atividades. Aliás, a motivação de participação em reuniões por causa de temas ligados a financiamentos leva apenas $40 \%$ dos entrevistados que disseram participar das reuniões, cabendo a outros motivos o comparecimento dos $60 \%$ restantes. Um entrevistado que disse participar de reuniões do APL comentou que apenas em uma reunião ouviu o tema financiamentos ser tratado. Muitos sequer conhecem a existência de linhas de financiamento específicas para APLs, ainda que boa parte dos entrevistados seja formada por empresas de pequeno porte, com parcos recursos e carentes de capital de giro. 
Cenário muito parecido foi encontrado em Nova Friburgo. Apesar de ser o mais institucionalizado dos três, e também o mais antigo, na percepção de apenas $10 \%$ dos empresários entrevistados o comparecimento nas reuniões do APL é significativo. Dos entrevistados, $40 \%$ afirmaram participar das reuniões e, destes, $2 / 3$ disseram que suas opiniões são ouvidas, e um entrevistado assinalou que acredita que o fato de ser relativamente pouco ouvido decorre do reduzido porte de sua empresa. Verdadeira ou não essa afirmação, há uma percepção de que nem todos são iguais naquele arranjo, e que o grau de influência nos rumos da coletividade é proporcional ao poder econômico de cada um. Um empresário entrevistado afirmou não saber como se estruturam tais reuniões e ações do seu APL, pois "não recebe convites para participar". Um dos que disseram participar informou que passou um tempo afastado e voltou a frequentar as reuniões. A pouca organização, comunicação e coletividade no APL, além da não sindicalização, foram apontados por alguns como os principais motivos de não participação em reuniões. Um entrevistado também afirmou que muitos participantes dessas reuniões são representantes de instituições e entidades, ao invés de empresários, o que dispersa, em seu entendimento, o foco das reuniões.

Houve um entrevistado que assinalou deficiências gerenciais nas empresas, que eram "geralmente conduzidas por ex-funcionários de outras empresas", com pouca cultura para o associativismo e a cooperação. A motivação de participação em temas ligados a financiamentos das empresas, nas reuniões de APL, leva apenas $25 \%$ dos entrevistados a participarem das reuniões, cabendo a outros motivos o comparecimento dos $75 \%$ restantes que disseram participar das reuniões. No APL de Cabo Frio uma postura mais ativa junto aos bancos foi apontada como existente por apenas 10\% dos entrevistados e 30\% demonstraram não saber que existem tais atividades.

\section{Conclusões}

Este artigo avaliou a implantação e a operação de redes empresariais, estruturadas em arranjos produtivos locais em três polos de confecções fluminenses, localizados em Petrópolis, Nova Friburgo e Cabo Frio. A intenção implícita é a de contrapor a discussão teórica com a realidade prática, identificando possíveis dificuldades. Do ponto de vista teórico, existe um claro sequenciamento conceitual que parte de uma ética participativa e comunicativa, à luz das propostas de Habermas (1987), e alcança a transformação de um entorno social carente e não tratado pelo braço do Estado. Essa linha de raciocínio, positiva 
e negativa por ser transformadora revolucionária, é vista pela teoria como uma esperança, capaz de oferecer uma alternativa às ausências do Estado e às limitações do mercado no trato da coisa social.

Todavia, a intervenção na realidade de algum conceito normalmente traz surpresas e desalinhamentos que, se não considerados e corrigidos, podem reduzir o potencial transformador das ideias. Afinal, a transcendência do que é ideal nem sempre espelha a imanência da experiência vivida.

Por meio deste artigo foi possível identificar que muito dessa possível lacuna de fato existe. As definições propostas por Lastres e Cassiollato (2006), Mercklé (2004), Castells (1999) e Granoveter (2000) foram claramente encontradas nos territórios estudados, de acordo com o exposto no referencial teórico. Contudo, as expectativas de Tenório e colaboradores (2008), Tenório (2007), Hitt e colaboradores (2005), Détrie (1999) e Britto (2004), se não foram totalmente negadas, o foram em parte.

Nos três APLs foi possível perceber uma ausência importante de um sentido irrestrito de confiança intracoletividade. Ainda que vários entrevistados tenham asseverado a existência de um espírito de grupo, houve a constatação de que práticas avessas à negociação contínua e aberta entre os diversos atores são comuns. A desconfiança por conta de uma concorrência por vezes predatória, o sentimento de que nem todos possuem o mesmo peso na tomada de decisão, a participação oscilante e escassa nas reuniões, a falta de consenso acerca dos interesses coletivos e a falta de entendimento do que, verdadeiramente, representam os conceitos de rede e de arranjo enfraquecem o seu potencial transformador. A isso deve ser acrescentado o papel das instituições oficiais, que muitas vezes buscam auxiliar a institucionalização e a operação das redes, mas acabam por imprimir, em sua ação, o peso da tecnocracia, o que impõe de forma exógena os processos e os destinos, que deveriam ser conduzidos e definidos pelo grupo. Exemplo disso é a oferta de cursos "de prateleira", ou de linhas de financiamento nem sempre adequadas à realidade de pequenos produtores, ainda que, para os maiores, funcionem a contento. Deve-se ressaltar, contudo, que a parceria entre os atores produz resultados, ainda que aquém do esperado, como é o caso do APL de Petrópolis onde, com a participação do Senai, foram criados cursos gratuitos de qualificação de mão de obra para a comunidade. O mais relevante foi a criação da escola de Costureiras.

No que se refere ao processo de participação e de tomada de decisão, foi identificado nas entrevistas corridas em Cabo Frio, mas também pontuado nos outros dois APLs, um centralismo nos órgãos que formatam suas respectivas governanças, com algumas reclamações por parte de empresários, principalmente os menores, quanto a seu alijamento. Não ficou claro se tal afastamento 
era, de fato, inevitável por conta de seu pequeno poder financeiro, ou se era algo espontâneo.

No entanto, há fortes indícios de que a cooperação existe. Este é o caso mais visível em Nova Friburgo, na época de ser organizada uma feira de alcance nacional, a Fevest. Nesse momento, as sugestões contidas na teoria, de um caminho de construção coletiva, encontram parelha na realidade estudada. A criação, por parte do Banco do Brasil, de uma linha de financiamento específica para APLs, o BB Giro APL, também pode ser interpretado como um passo de aproximação entre estruturas oficiais e as carências dessas redes. Um aprofundamento dessa parceria esbarra na ausência de uma estrutura de gestão confiável e eficiente, o que inclui aspectos contábeis. Em outros termos, é difícil imaginar um órgão público, no caso financeiro, dialogando e disponibilizando recursos para empresários que, muitas vezes, confundem os interesses de sua empresa com os seus interesses individuais.

Assim, percebe-se que há avanços importantes naquelas comunidades por conta da existência das redes empresariais apresentadas, tanto do ponto de vista social quanto técnico. Contudo, as características dos próprios empresários, do ponto de vista cultural, mercadológico e financeiro, bem como a heterogeneidade dos atores envolvidos, em termos de interesses e de tamanho, reduzem o potencial dialógico e transformador presente no conceito. Assim, devem ser conduzidas ações de solidificação do conceito de APL, e criados mecanismos capazes de aumentar a confiança mútua, antes de apresentar e implementar soluções bem-sucedidas em outras realidades e países.

Como agenda de pesquisa, propõe-se o estudo vertical ao longo do tempo dessas comunidades, visando acompanhar a evolução das redes empresariais existentes. Como já constatado no decorrer da pesquisa, a destruição e posterior recriação fazem parte da rotina desses arranjos, e acompanhá-los no processo de aprendizagem pode lançar luzes sobre outros APLs existentes no país.

\section{Referências}

BALESTRIN, A.; VARGAS, L. M. A dimensão das redes horizontais de PME's: teorizações e evidências. In: ENCONTRO DE ESTUDOS DE ESTRATÉGIAS, 1. Anais eletrônicos... Curitiba, Paraná, 2003. CD-ROM.

BRITTO, Jorge. Cooperação interindustrial e redes de empresas. In: KUPFER, D.; HASENCLEVER, L. (Orgs.). Economia industrial: fundamentos teóricos e práticos no Brasil. Rio de Janeiro: Campus, 2002. 
CASSIOLATO, J. E.; LASTRES, H. M. M. O foco em arranjos produtivos e inovativos locais de micro e pequenas empresas. In: LASTRES, H. M. M. (Org.). Pequena empresa: cooperação e desenvolvimento local. Rio de Janeiro: Relume-Dumará, UFRJ/Instituto de Economia, 2003.

CASTELLS, M. A sociedade em rede. 10. ed. São Paulo: Paz e Terra, 2007.

CURRIEN, N. Économie des reseaux. Paris: La Découvert, 2005.

DÉTRIE J. P. (Org.). Strategor — politique générale de l'entreprise. Paris: Dunod, 1999.

FISCHER, T. Gestão contemporânea, cidades estratégicas: aprendendo com fragmentos e reconfigurações do local. In: FISCHER, T. (Org.). Gestão estratégica: cidades estratégicas e organizações local. Rio de Janeiro: FGV, 1996.

FLEURY, S.; OUVERNEY, A. M. Gestão de redes - a estratégia de regionalização da política de saúde. Rio de Janeiro: FGV, 2007.

GEREFFI, G. Competitividade e redes na cadeia produtiva do vestuário na América do Norte. Revista Latino-Americana de Estudos do Trabalho, v. 4, n. 6, p. 101-127, 1998.

GILLY, J.-P.; PECQUER, B. La dimension locale de la régulation. In: BOYER, R.; SAILLARD, Y. Théorie de la regulation et Ėtat des savoir. Paris: La Découverte, 1995.

GONÇALVES, Reinaldo. A empresa transnacional. In: KUPFER, D.; HASENCLEVER, L. (Orgs.). Economia industrial: fundamentos teóricos e práticos no Brasil. Rio de Janeiro: Campus, 2002.

GRANOVETTER, M. S. Le marché autrement. Paris: Desclée de Brouwer, 2000.

GUERREIRO RAMOS, A. A nova ciência das organizações - uma reconceituação da riqueza das nações. Rio de Janeiro: FGV, 1989.

HABERMAS, J. Teoria de la acción comunicativa: racionalid de la acción y racionalización social, Madrid: Taurus, 1987. v. 1.

HEINELT, H.; KÜBLER, D. (Orgs.) Metropolitan gouvernance. Capacity, democracy and the dynamics of place. New York: Routledge, 2005.

HITT, M. A.; IRELAND, R. D.; HOSKISSON, R. Administração estratégica: competitividade e globalização. São Paulo: Thompson, 2005.

JUNQUEIRA, Luciano. Gestão de negócios um saber interdisciplinar. In: JUNQUEIRA, Luciano (Org.). Desafios da modernização portuária. São Paulo: Aduaneiras, 2002.

LASTRES, H. M. M.; CASSIOLATO, J. E. Rede de pesquisa em sistemas produtivos e inovações locais, glossário de arranjos e sistemas produtivos e inovações locais. Rio 
de Janeiro: IE/UFRJ, Sebrae, 2006. Disponível em: <www.ie.ufrj.br/redesist>. Acesso em: 25 jun. 2008.

LE GALÈS, Patrick. (dossier rélisé par) Gouvernement et gouvernance des territoires. Problèmes politiques et sociaux, n. 922. Paris: La Documentation Française, 2006.

MAEHLER, Alisson; CASSANEGO Jr., Paulo. O programa de apoio aos arranjos produtivos locais (APL'S) no RS: uma política de criação de vantagem competitiva às empresas de micro e pequeno porte. In: ENCONTRO DE ESTUDO EM ESTRATÉGIA, 4. Anais eletrônicos... Recife: Anpad, 2009. 1 CD-ROM.

MERCKLÉ, P. Sociologie des réseaux sociaux. Paris: La Découverte, 2004.

MYTELKA, Lynn; FARINELLI, Fulvia. De aglomerados locais a sistemas de inovação. In: LASTRES, H. et al. (Orgs.). Conhecimento, sistemas de inovação e desenvolvimento. Rio de Janeiro: UFRJ, 2005.

OLIVEIRA, Sergio; BRUNI, Adriano. Consórcios de exportação de pequenas e médias empresas de moda praia localizadas em arranjos produtivos locais - caminho para internacionalização? In: ENCONTRO DE ESTUDO EM ESTRATÉGIA, 4. Anais eletrônicos... Recife: Anpad, 2009. 1 CD-ROM.

SEBRAE. Arranjos produtivos locais - perfil das concentrações de atividades econômicas no estado do Rio de Janeiro. Rio de Janeiro: Sebrae, 2004.

SCHMITZ, Hubert. Aglomerações produtivas locais e cadeias de valor: como a organização das relações entre empresas influencia o aprimoramento produtivo. In: LASTRES, H. et al. (Orgs.). Conhecimento, sistemas de inovação e desenvolvimento. Rio de Janeiro: UFRJ, 2005.

TENÓRIO, F. G. (Org.). Responsabilidade social empresarial — teoria e prática. Rio de Janeiro: FGV, 2004. 2007.

(Org.). Cidadania e desenvolvimento local. Rio de Janeiro: FGV; Ijuí: Unijuí,

; VILLELA, L. E.; DIAS, Anderson, F. Critérios para a avaliação de processos decisórios participativos deliberativos na implementação de políticas públicas. In: ENCONTRO DE ADMINISTRAÇÃO PÚBLICA E GOVERNANÇA, 3., 2008, Salvador. Anais... Curitiba: Anpad, 2008.

VALLE, M. R. A utilização da lógica fuzzy para análise de fatores endógenos e exógenos em um arranjo produtivo local: o caso da moda praia de Cabo Frio. 2007. Dissertação (Mestrado em Administração) - Universidade Estácio de Sá, Rio de Janeiro. 
VILLELA, L. E. Estratégias de cooperação e competição de organizações em rede - uma realidade pós-fordista? In: ENANPAD, 29. Brasília, set. 2005. Anais eletrônicos... Rio de Janeiro: Anpad, 2005. 1 CD-ROM.

et al. O papel e o potencial das instituições na governança do arranjo produtivo local de confecções de moda intima de Nova Friburgo/RJ. In: ENCONTRO DE ADMINISTRAÇÃO PÚBLICA E GOVERNANÇA/ANPAD, 2004, Rio de Janeiro. Anais... Rio de Janeiro, 2004.

; VEIGA, D. R. Características essenciais à formação de redes de empreendedores no APL de confecções de roupas íntimas de Nova Friburgo-RJ: uma análise comparativa entre os pressupostos teóricos e a realidade local. In: SIMPÓSIO DE GESTÃO E INOVAÇÃO TECNOLÓGICA/ANPAD. Gramado, out. 2006. Anais eletrônicos... Rio de Janeiro: Anpad, 2006. 1 CD-ROM. 